\title{
Single Coronary Artery Anomaly: A Case Report and Review of Literature
}

\author{
Ayman Elbadawi - Basarat Baig - Islam Y. Elgendy · Erfan Alotaki · \\ Ahmed H. Mohamed · Kirolos Barssoum • David Fries • \\ Muhammad Khan · Rami N. Khouzam
}

Received: November 21, 2017 / Published online: February 6, 2018

(c) The Author(s) 2018. This article is an open access publication

\section{ABSTRACT}

Introduction: Single coronary artery is a rare anomaly, which is usually associated with other cardiac congenital abnormalities.

Case Report: A 56-year-old female presented with unstable angina. The patient reported complaints of typical chest pain on exertion few months prior to presentation, which progressed to become at rest. The pain was associated palpitations and dizziness. Past medical history was significant for hypertension and hyperlipidemia. Vital signs were stable. Physical examination was non-remarkable. Electrocardiogram

Enhanced content To view enhanced content for this article go to https://doi.org/10.6084/m9.figshare. 5813043.

A. Elbadawi · B. Baig · E. Alotaki · A. H. Mohamed . K. Barssoum

Internal Medicine Department, Rochester General Hospital, Rochester, NY, USA

I. Y. Elgendy $(\bowtie)$

Division of Cardiovascular Medicine, University of Florida, Gainesville, FL, USA

e-mail: iyelgendy@gmail.com

D. Fries $\cdot$ M. Khan

Sands Constellation Heart Institute, Rochester

General Hospital, Rochester, NY, USA

\section{R. N. Khouzam}

Department of Medicine, Division of Cardiology, University of Tennessee Health Science Center,

Memphis, TN, USA showed normal sinus rhythm, with intermittent episodes of sinus bradycardia, and non-specific T-wave changes. Trans-thoracic echocardiogram showed normal left ventricular function and no segmental wall-motion abnormalities. Selective coronary angiography showed a normal left main coronary artery arising from left coronary cusp. The left main branched to a normal left anterior descending artery and to the left circumflex artery; a large vessel which supplied also the territory of the right coronary artery (RCA) through its terminal extension. Aortography showed absence of RCA with no other vessels arising from the right or noncoronary cusps. The patient was managed conservatively and discharged home with resolution of symptoms.

Conclusions: We report a rare case of isolated single coronary artery with absent RCA. The patient presented with unstable angina, and was managed conservatively. Cardiologists should be aware of this rare condition, which carries a potential risk of sudden cardiac death.

Keywords: Absent right coronary artery; Congenital heart disease; Single coronary artery anomaly

\section{BACKGROUND}

Single coronary artery (SCA) is a rare congenital anomaly where only one coronary artery arises 
from a single coronary ostium to supply the entire heart $[1,2]$. It is usually associated with other cardiac abnormalities. SCA has variable presentation, ranging from mild non-specific symptoms up to sudden cardiac death [1].

\section{CASE REPORT}

A 56-year-old woman presented to our hospital with unstable angina. The patient complained of progressive substernal chest pain on exertion that started a few months prior to presentation, and then progressed to become more frequent and at rest. She also had associated palpitations and dizziness. Her past medical history was significant for hypertension and hyperlipidemia. On admission, vital signs showed a heart rate of $80 \mathrm{bpm}$, blood pressure of $130 / 90 \mathrm{mmHg}$, and temperature of $36.6^{\circ} \mathrm{C}$. Physical examination was otherwise unremarkable. Electrocardiogram showed normal sinus rhythm, with non-specific T-wave changes. Trans-thoracic echocardiogram showed normal left ventricular function and no segmental wallmotion abnormalities. Blood work showed negative cardiac troponin as well as normal complete blood count and metabolic profile.

We decided to proceed with a coronary angiogram given her clinical presentation with unstable angina. Selective coronary
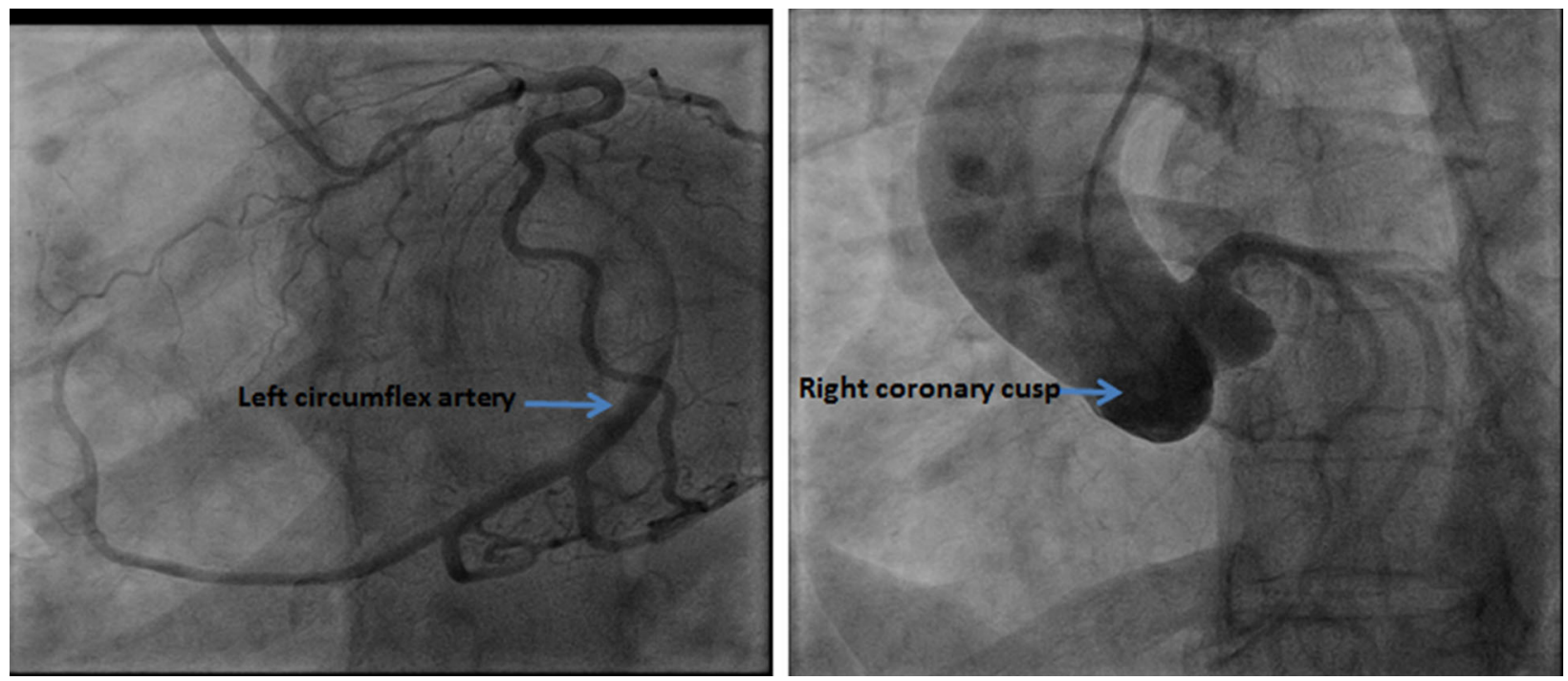

Fig. 1 a Coronary angiography showing left circumflex artery supplying RCA region. b Aortography showing absent RCA. $R C A$ right coronary artery 
coronary vasculature ranges from 0.1 to $0.9 \%$ $[5,6]$, with most of the published cases reporting RCA originating from the proximal or middle portion of the LAD.

Lipton et al. [7] originally proposed the angiographic classification of SCA, which was later modified by Yamanaka et al. (Table 1) [4]. This classification takes into account the origin of the ostium from the sinus of Valsalva, anatomical course of the vessel, and the course of the transverse trunk. Alphabets $\mathrm{R}$ or $\mathrm{L}$ are used to identify the ostial origin of the vessel, roman numerals I, II, or III are used to represent the anatomical distribution of the vessel, and letters A, B, P, S, and C are used to delineate the course of the vessel with respect to the pulmonary artery and the aorta [4]. Per this system, our patient would be classified as LIA.

Most patients are asymptomatic at the time of diagnosis, and cases of SCA are usually found incidentally on coronary angiography. Many patients might have atypical chest pain or nonspecific symptoms, with absence of obstructive coronary artery disease and negative workup for ischemia [8]. Others may present with features of typical chest pain, sudden death especially during exercise, syncope, palpitations, ventricular tachycardia, and myocardial infarction [8]. Certain anomaly classifications usually have a benign clinical course, such as RI, LI types. Meanwhile, the aberrant coronary artery courses between the outflow tracts such as R/LIIB or RIII, which makes them more prone to serious clinical complications [9]. The underlying pathophysiology could be related to the dilatation of the great outflow tracts during exercise, with secondary compression of the aberrant coronary artery along their varied course [9]. Other features, like acute take-off angle of the anomalous vessel, slit-like orifice, and proximal intramural course, are characteristics that can predispose to anginal symptoms and sudden death during exertion $[5,8]$.

Basso et al. [10] identified 27 cases of sudden cardiac death in young adults with congenital coronary anomalies in a retrospective review. It was observed that the patients with coronary arteries originating from contralateral sinuses were more likely to die during exertional activity. This is theorized to be secondary to compression of the anomalous vessel between the aorta and the pulmonary artery during exercise because of the dilation of the latter two vessels $[11,12]$. Taylor et al. [5] looked at the records of 242 deceased patients with isolated congenital coronary anomalies and found that one-third of the patients suffered sudden cardiac death, and half of these were exercise-related deaths. Patients younger than 30 years of age were significantly more likely to suffer from sudden cardiac death compared to older patients. Younger patients were also more likely to die suddenly during physical exertion.

Coronary angiography remains the gold standard for diagnosis and classification. Echocardiography is useful mainly to delineate other structural abnormalities accompanying the SCA. Computed tomography angiography offers a less-invasive imaging modality despite requiring administration of contrast media.

Table 1 Lipton's classification of single coronary artery

\begin{tabular}{lll}
\hline $\begin{array}{l}\text { Originating from } \\
\text { right cusp }\end{array}$ & Description & $\begin{array}{l}\text { Originating from } \\
\text { left cusp }\end{array}$ \\
\hline RI & $\begin{array}{l}\text { Solitary vessel arising from either the left or right coronary cusp, following the } \\
\text { course of either a normal right or left coronary artery }\end{array}$ & LI \\
RIIA & $\begin{array}{l}\text { Divided into } 3 \text { types depending on the relationship of the aberrant vessel to the } \\
\text { great vessels. Type A courses anterior to the pulmonary trunk. Type B travels }\end{array}$ & LIIA \\
RIIIB & $\begin{array}{l}\text { between the aorta and pulmonary trunk. Type P travels posterior to the aorta } \\
\text { RIIP }\end{array}$ & LIIP \\
RIII & Absent left coronary artery with the left anterior descending and circumflex & \\
& arteries arising from the common trunk originating from right coronary cusp & \\
\hline
\end{tabular}


Cardiovascular magnetic resonance (CMR) is a suitable alternative investigation for assessing coronary anatomy. Advantages extended by CMR include lack of exposure to ionizing radiations, no need to use iodinated or ionized intravenous contrast media, no restrictions imposed by body habitus, simultaneous evaluation of multiple parameters of cardiovascular anatomy, perfusion and function, along with the ability to achieve high spatial and temporal resolutions to better assess structural abnormalities [13].

Treatment options include conservative medical management, percutaneous coronary intervention (PCI) with stent placement, and surgical correction. Most asymptomatic patients do not require invasive therapy and should be managed with strict control of risk factors. Given the variety of anatomical presentations, a multidisciplinary approach involving cardiothoracic surgery and interventional cardiology can be considered to determine the best course of action in symptomatic patients. Presentations with unstable angina, similar to our case, have been previously described in cases of SCA. While some of those patients improved with medical treatment, others had obstructive coronary disease requiring intervention.

PCI in cases of SCA poses certain technical challenges. The abnormal origin and course in cases of SCA lead to difficulties in cannulation of the coronary ostium as well as difficulties in providing optimal catheter support during PCI [14]. Awareness of those variations is important for catheter-based treatment. Rudan et al. [13] successfully performed PCI with stent placement in a case of SCA where RCA originated as extension of left coronary vasculature. Kafkas et al. [15] reported successful stent placement in an L1 type SCA. Other case reports also demonstrated successful management of similar lesions by PCI $[14,16]$.

Surgical options include osteoplasty, coronary artery bypass grafting (CABG) of the anomalous artery, re-implantation of the anomalous artery to the aorta, and pulmonary artery translocation [5, 17]. Rinaldi et al. [17] reported the management of eight cases of anomalous RCA plus slit ostium with ostial widening. Others reported successful management by CABG in two symptomatic patients with SCA complicated by stenotic lesions along the vessel course [18]. Pulmonary artery translocation is usually reserved for patients with coronary arteries arising from the contralateral coronary sinus without stenotic or slit-like lesions along the vessel [5].

Due to the lack of stenotic lesions, acute angle cut-off and slit-like lesions, our patient was managed medically with risk factor control.

\section{CONCLUSIONS}

We report a rare case of SCA, a rare congenital abnormality. Patients are usually asymptomatic, however, may present with typical chest pain, ventricular fibrillation, or myocardial infarction. Cardiologists should be aware of this rare condition, which has been associated with sudden cardiac death in young individuals. Management usually involves a multi-disciplinary approach with interventionists and surgeons aiming for an individualized plan based on presentation and anatomy of each case.

\section{ACKNOWLEDGEMENTS}

Funding. No funding or sponsorship was received for this study or publication of this article.

Authorship. All named authors meet the International Committee of Medical Journal Editors (ICMJE) criteria for authorship for this article, take responsibility for the integrity of the work as a whole, and have given their approval for this version to be published.

Disclosures. Ayman Elbadawi, Basarat Baig, Islam Y. Elgendy, Erfan Alotaki, Ahmed H. Mohamed, Kirolos Barssoum, David Fries, Muhammad Khan, and Rami N. Khouzam have no conflicts of interest to declare.

Compliance with Ethics Guidelines. Informed consent was obtained from the patient for reporting this rare case. 
Data Availability. The datasets during and/ or analyzed during the current study are available from the corresponding author on reasonable request.

Open Access. This article is distributed under the terms of the Creative Commons Attribution-NonCommercial 4.0 International License (http://creativecommons.org/licenses/ by-nc/4.0/), which permits any noncommercial use, distribution, and reproduction in any medium, provided you give appropriate credit to the original author(s) and the source, provide a link to the Creative Commons license, and indicate if changes were made.

\section{REFERENCES}

1. Desmet W, Vanhaecke J, Vrolix M, Van de Werf F, Piessens J, Willems J, De Geest $\mathrm{H}$. Isolated single coronary artery: a review of 50,000 consecutive coronary angiographies. Eur Heart J. 1992;13:1637-40.

2. Shrivastava S, Mohan J, Mukhopadhyay S, Rajani M, Tandon R. Coronary artery anomalies in tetralogy of Fallot. Cardiovasc Interv Radiol. 1987;10:215-8.

3. Yuksel S, Meric M, Soylu K, Gulel O, Zengin H, Demircan S, Yilmaz O, Sahin M. The primary anomalies of coronary artery origin and course: a coronary angiographic analysis of 16,573 patients. Exp Clin Cardiol. 2013;18:121.

4. Yamanaka O, Hobbs RE. Coronary artery anomalies in 126,595 patients undergoing coronary arteriography. Catheter Cardiovasc Interv. 1990;21:28-40.

5. Taylor AJ, Rogan KM, Virmani R. Sudden cardiac death associated with isolated congenital coronary artery anomalies. J Am Coll Cardiol. 1992;20:640-7.

6. Kim JM, Lee OJ, Kang I, Huh J, Song J, Kim G. A rare type of single coronary artery with right coronary artery originating from the left circumflex artery in a child. Korean J Pediatr. 2015;58:37-40.

7. Lipton MJ, Barry WH, Obrez I, Silverman JF, Wexler L. Isolated single coronary artery: diagnosis, angiographic classification, and clinical significance. Radiology. 1979;130:39-47.

8. Akcay A, Tuncer C, Batyraliev T, Gokce M, Eryonucu B, Koroglu S, Yilmaz R. Isolated single coronary artery. Circ J. 2008;72:1254-8.
9. Evrengul H, Ozcan EE, Turhan H, Ozturk A. Single coronary artery originating from the right sinus of Valsalva and hypoplastic left anterior descending artery: an extremely rare combination of congenital coronary artery anomalies. Exp Clin Cardiol. 2012;17:243.

10. Basso C, Maron BJ, Corrado D, Thiene G. Clinical profile of congenital coronary artery anomalies with origin from the wrong aortic sinus leading to sudden death in young competitive athletes. J Am Coll Cardiol. 2000;35:1493-501.

11. Yurtdas M, Gülen O. Anomalous origin of the right coronary artery from the left anterior descending artery: review of the literature. Cardiol J. 2012;19:122-9.

12. Hundley WG, Bluemke DA, Finn JP, Flamm SD, Fogel MA, Friedrich MG, Ho VB, Jerosch-Herold M, Kramer CM, Manning WJ. ACCF/ACR/AHA/NASCI/ SCMR 2010 expert consensus document on cardiovascular magnetic resonance: a report of the American College of Cardiology Foundation Task Force on Expert Consensus Documents. J Am Coll Cardiol. 2010;55:2614-62.

13. Rudan D, Todorovic N, Starcevic B, Raguz M, Bergovec M. Percutaneous coronary intervention of an anomalous right coronary artery originating from the left coronary artery. Wien Klin Wochenschr. 2010;122:508-10.

14. Çalışkan M, Çiftçi Ö, Güllü H, Alpaslan M. Anomalous right coronary artery from the left sinus of Valsalva presenting a challenge for percutaneous coronary intervention. Turk Kardiyol Dern Ars. 2009;37:44-7.

15. Kafkas N, Triantafyllou K, Babalis D. An isolated single LI type coronary artery with severe LAD lesions treated by transradial PCI. J Invasive Cardiol. 2011;23:E216-8.

16. Pourafkari L, Taban M, Ghaffari S. Anomalous origin of right coronary artery from distal left circumflex artery: a case study and a review of its clinical significance. J Cardiovasc Thorac Res. 2014;6:127.

17. Rinaldi RG, Carballido J, Giles R, Del Toro E, Porro R. Right coronary artery with anomalous origin and slit ostium. Ann Thorac Surg. 1994;58:828-32.

18. Izumiyama O, Yamashita A, Sugimoto S, Baba M, Hasegawa T. Coronary artery bypass grafting in two patients with single coronary artery. Kyobu geka Jpn J Thorac Surg. 1999;52:143-7. 